\title{
Sample series of direct running ceiling slabs in multifunctional buildings with their defects and analyzing the causes of these defects
}

\author{
Luboš Podolka ${ }^{1, *}$ \\ ${ }^{1}$ University of technology and economics in Czech Budejovice, Department of civil engineering, \\ 37001 Czech Budejovice, Czech Republic
}

\begin{abstract}
With the aid of photographs, the report shows a range of damaged direct running ceiling slabs in multifunctional buildings, then analyses the cause of the defects and also gives instructions on how these arising defects could have been prevented or significantly reduced through a suitable design of the structure.
\end{abstract}

\section{Introduction}

Most newly constructed multifunctional buildings have an underground part designed as a parking garage, where the designed reinforced concrete ceiling structure consists of direct running slabs often protected only by coating against harsh environments and abrasion. Their design is thus created in terms of II.MS limiting crack width.

\section{4th SF ceiling construction in the Lighthouse building}

The numerical analysis was performed for a typical ceiling slab of an underground floor (parking) comprising one half of the ground plan of the subterranean part of the building. The analyzed slab with $0.250 \mathrm{~m}$ thickness has a rectangular shape with dimensions of 48.6 $\mathrm{x} 16.7 \mathrm{~m}$. Along the longitudinal edges it is supported by bearing concrete walls with a thickness of 0.200 and $0.300 \mathrm{~m}$. Furthermore, the slab is supported by columns in a $8.1 \mathrm{x}$ $7.5 \mathrm{~m}$ grid. The whole storey or a typical field of $8.1 \mathrm{~m}$ length has been alternatively solved in the numerical models. The scheme of the slab geometry and layout is shown in the following figures.

\footnotetext{
*Corresponding author: podolka@mail.vstecb.cz
} 


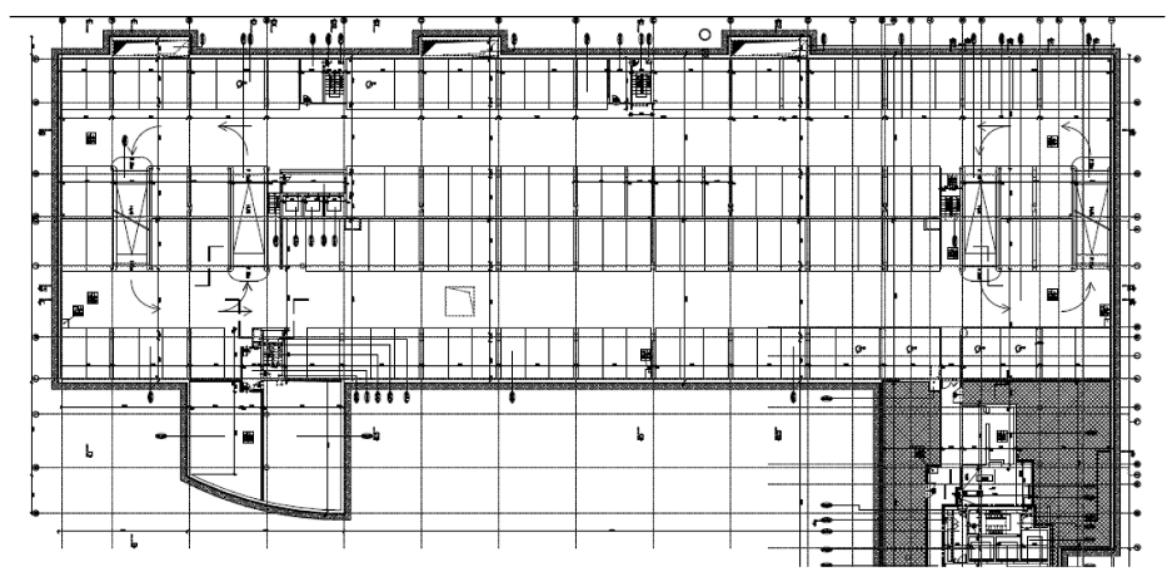

Fig. 1. Ground plan of the overhead slab in the 4th SF

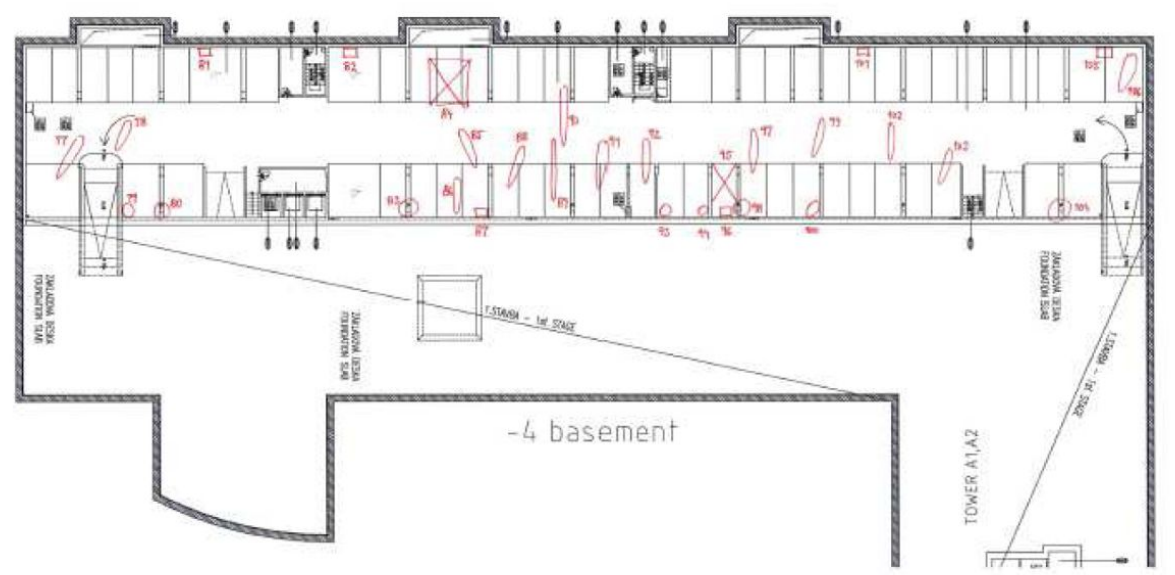

Fig. 2. The overhead slab in the 4th SF with the sketch of cracks (provided by the client)

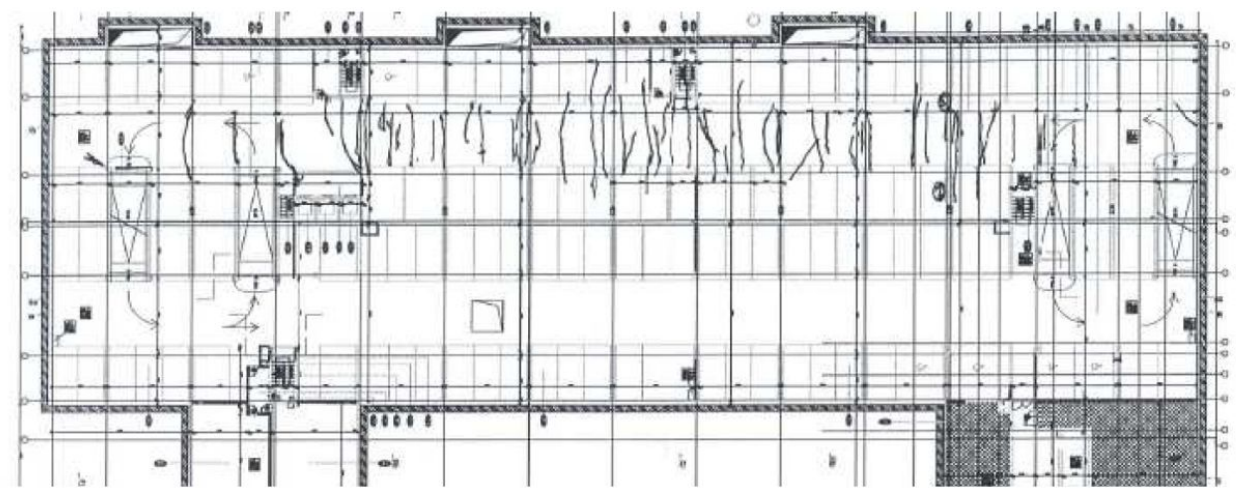

Fig. 3. The overhead slab in the 4th SF with the crack pattern in the floor (top surface), provided by the Klokner Institute 


\subsection{Numerical model, loading cases}

For the conversion of the supporting structure in accordance with ČSN 730035 Loading of Building Structures and ČSN 731201 Design of Concrete Structures the FEAT 2000 software was used, in which a $3 \mathrm{D}$ model of the ceiling structure was created and critical load conditions modeled.

At the same time the company "Cervenka Consulting Company from Prague, Czech Republic, http://www.cervenka.cz" performed a non-linear calculation of structures in ATENA.

This program enables, by means of advanced numerical methods, a realistic simulation of a response of reinforced concrete structures to the load and their damage. In particular, it is possible to trace in details the formation and growth of the tensile cracks in concrete, yielding of reinforcement, concrete crushing, and also to determine the ultimate loadcarrying capacity of the structure and its failure mode. Two kinds of slab models with bearing walls and columns were created and analyzed. The larger model (Fig. 4) comprises the whole slab of the parking floor. The smaller one (Fig. 5) represents one typical field of the central part of the slab (in the zone with the substantial occurrence of cracks). It has dimensions of $16.7 \times 8.1 \mathrm{~m}$ and includes the horizontal ceiling plate, 2 columns and side walls.

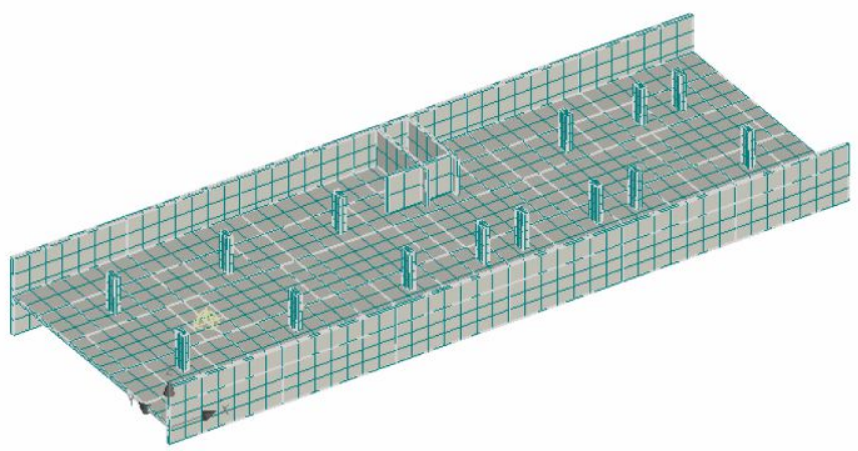

Fig. 4. Numerical model of the entire slab

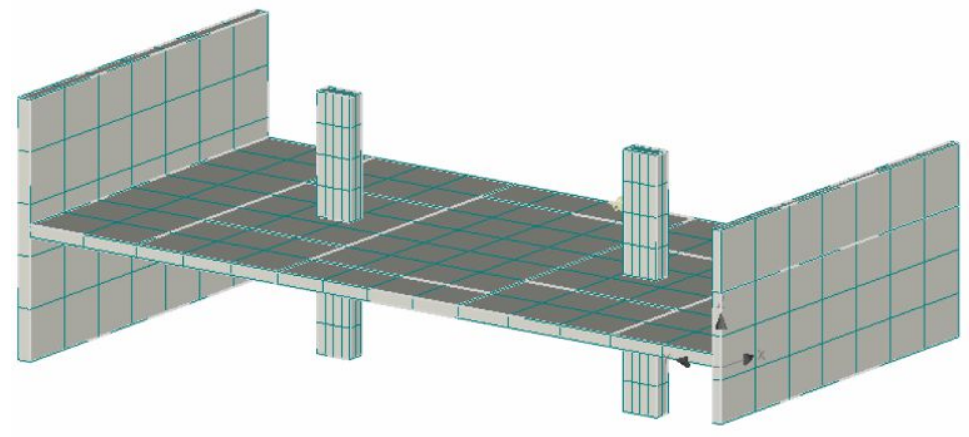

Fig. 5. Numerical model of a typical slab field

The created models were incrementally loaded by the dead load, shrinkage, permanent load and imposed service load. In the representative analysis a shrinkage of $150 \mu \mathrm{m} / \mathrm{m}$, a permanent load of $2.0 \mathrm{kN} / \mathrm{m} 2$ and service load of $2.5 \mathrm{kN} / \mathrm{m} 2$ have been considered. The regularly distributed service load was consequently increased until the failure of the structural model. During the whole analysis, the slab deflection and the crack widths were monitored. 

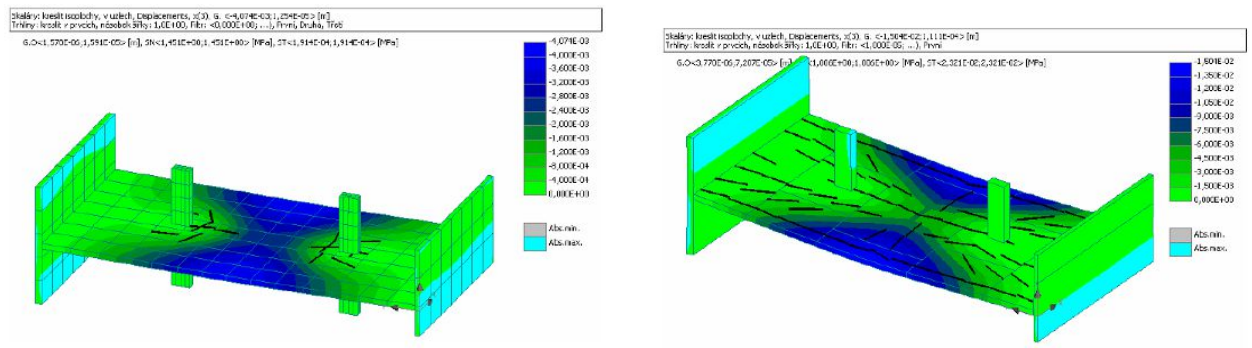

Fig. 6, 7. Vertical slab deflections at the service load level fig. on the left; in the second fig. Vertical slab deflections at the service load level with shrinkage. The fractures wider than $0.01 \mathrm{~mm}$ are drawn. All the calculated cracks are drawn.
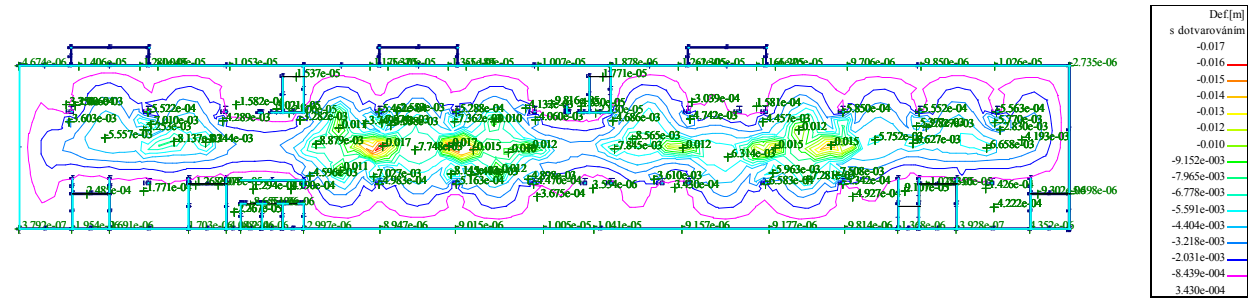

Fig. 8. Deformation of ceiling slabs in considering of standard concrete elasticity modulus
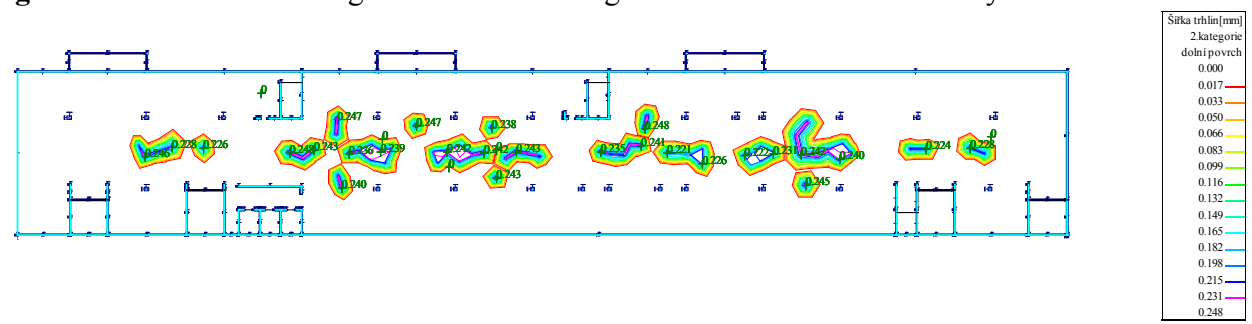

Fig. 9. The width of the cracks on the slab at the bottom surface when considering of the standard concrete elasticity modulus
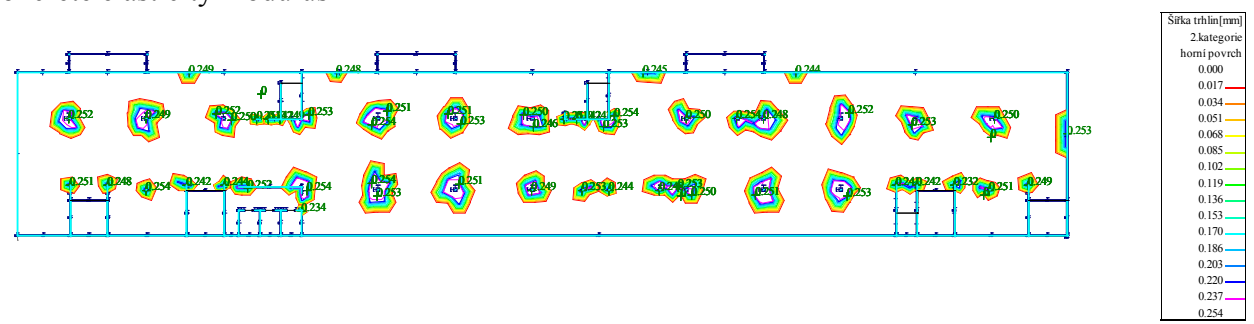

Fig. 10. Crack width in the slab on the upper surface in considering of standard concrete elasticity modulus

The actual measured crack widths and deflections were even greater than calculated, indicating errors also in the implementation structures (formwork decline, premature stripping, inadequate care, poor modulus of concrete elasticity, etc.).

Static modulus determined on specimens prepared from cores, reaching an average of $23.4 \mathrm{GPa}$. This value is lower than the corresponding properties of conventional concrete classes C 25/30. 
There fore if the modulus of concrete elasticity against the calculation of $32.5 \mathrm{GPa}$ is $23.4 \mathrm{GPa}$ lower, in this ratio the higher deformation and even cracks in the ratio of at least the elasticity modulus will increase.

$$
\begin{gathered}
\Delta=E n / E s=32.5 / 23.4=1.39 . \\
\text { deflection } 17 \times 1.39=23.6 \mathrm{~mm} \leq \text { flim }=26.8 \mathrm{~mm} \\
\text { cracks }=0.25 \times 1.39=0.35 \mathrm{~mm}
\end{gathered}
$$

(if there is no protected surface limit of $0.2 \mathrm{~mm}$, for a protected surface of max. $0.3 \mathrm{~mm}$ ).

\subsection{Conclusion on the analysis of ceiling slabs:}

Both the lack of reinforcement slabs and insufficient tending of the concrete contributed to the emergence of cracks, which led to a reduction in the concrete elasticity modulus.

\section{The ceiling slab above the 3rd basement level of the Gemini office building in Pankrác, Prague}

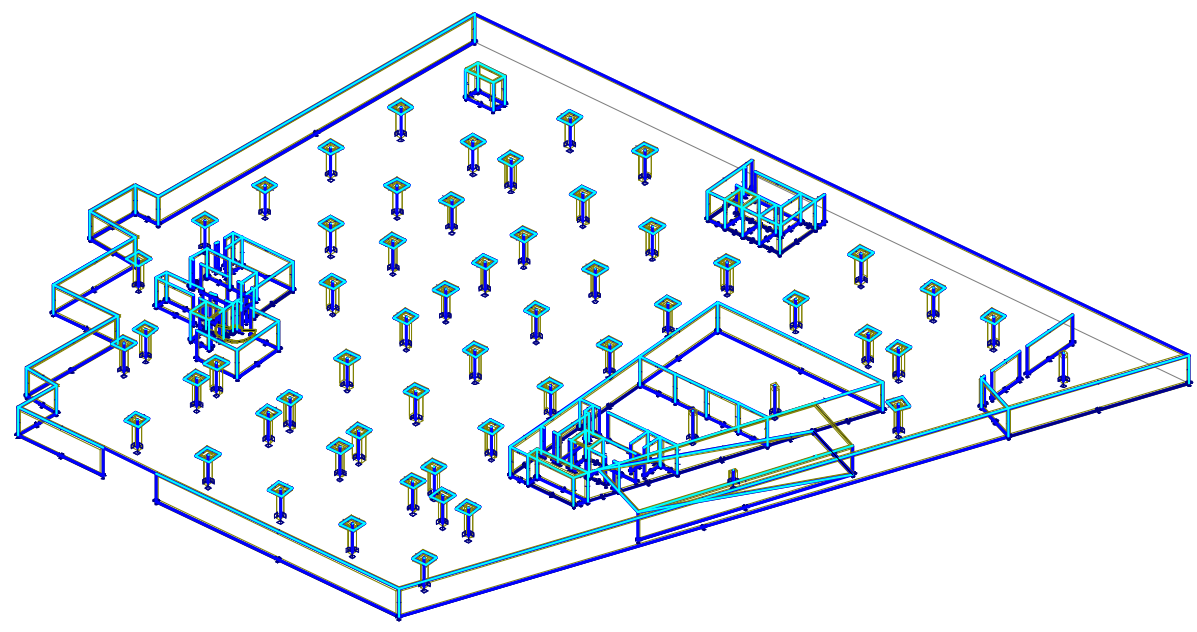

Fig. 11. 3D model

The slab thickness aspect of $0.230 \mathrm{~m}$ is irregular in shape with dimensions of about $80 \times 80 \mathrm{~m}$. It is held by supporting columns, with a typical axial distance of 8 meters, above, the columns usually made of a reinforced concrete head of $1.5 \times 1.5 \mathrm{~m}$, thickness measuring $0.150 \mathrm{~m}$. Regarding circumference the slab mounted on the supporting wall has a thickness of $0.300 \mathrm{~m}$. 


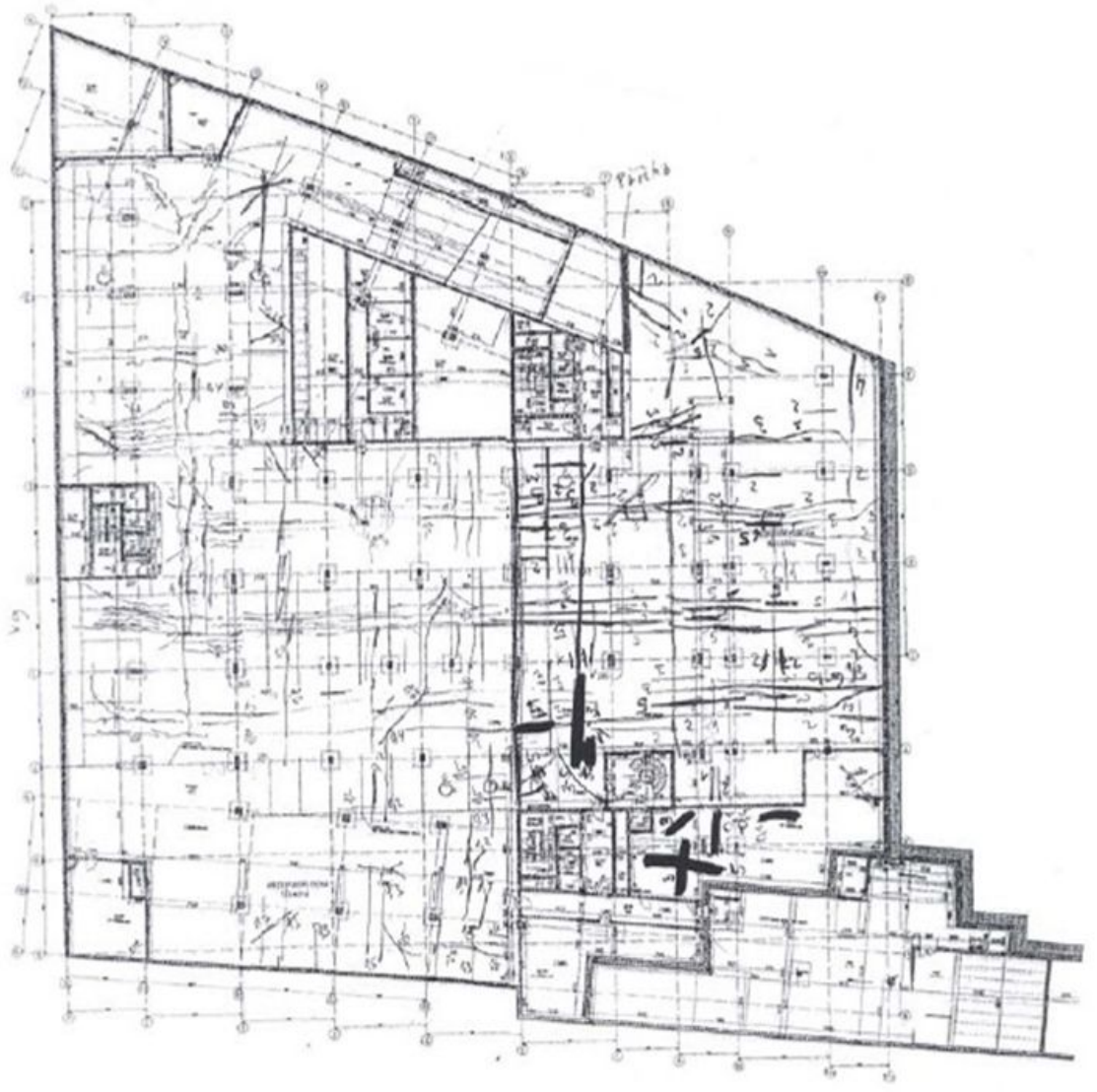

Fig. 12. Drawing of shaped ceiling slab shapes above the 3rd SF with drawn cracks

The design analysis was created using the FEAT model for comparison with the static calculation and the "Cervenka Consulting Company from Prague, Czech Republic, http://www.cervenka.cz" made a nonlinear analysis of the structures in ATENA.

For the purpose of verifying the behavior and tolerance of the ceiling slabs two slab models with supporting columns and heads were created. A smaller model (Fig. 13) was formed by the sectioned central portion of the slab (in areas with a high incidence of cracks) on 4 typical fields (approx. $16 \times 16 \mathrm{~m}$ ), with four columns and heads. The increased computational model (Fig. 14) is formed by part of the slab defined by shrinkage deflections.
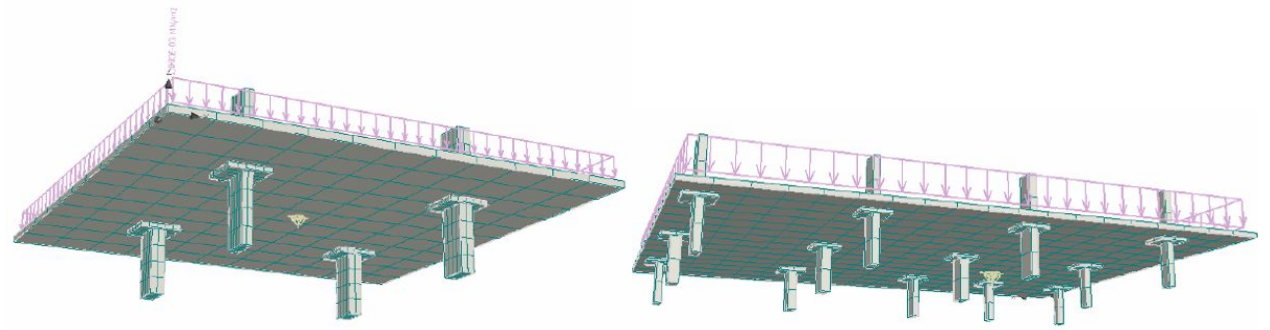

Fig. 13, 14. Model of typical slab fields

Model rendered through the larger arc of the 3rd SF 
ceiling slab

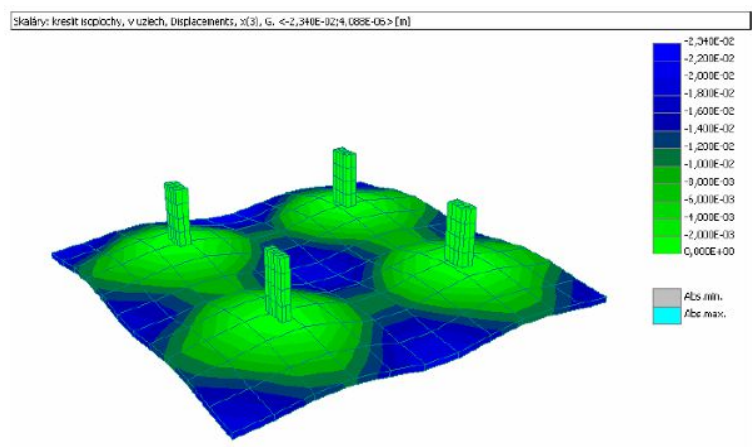

Fig. 15. The deflection area of the slab, the maximum deflection $23.4 \mathrm{~mm}$

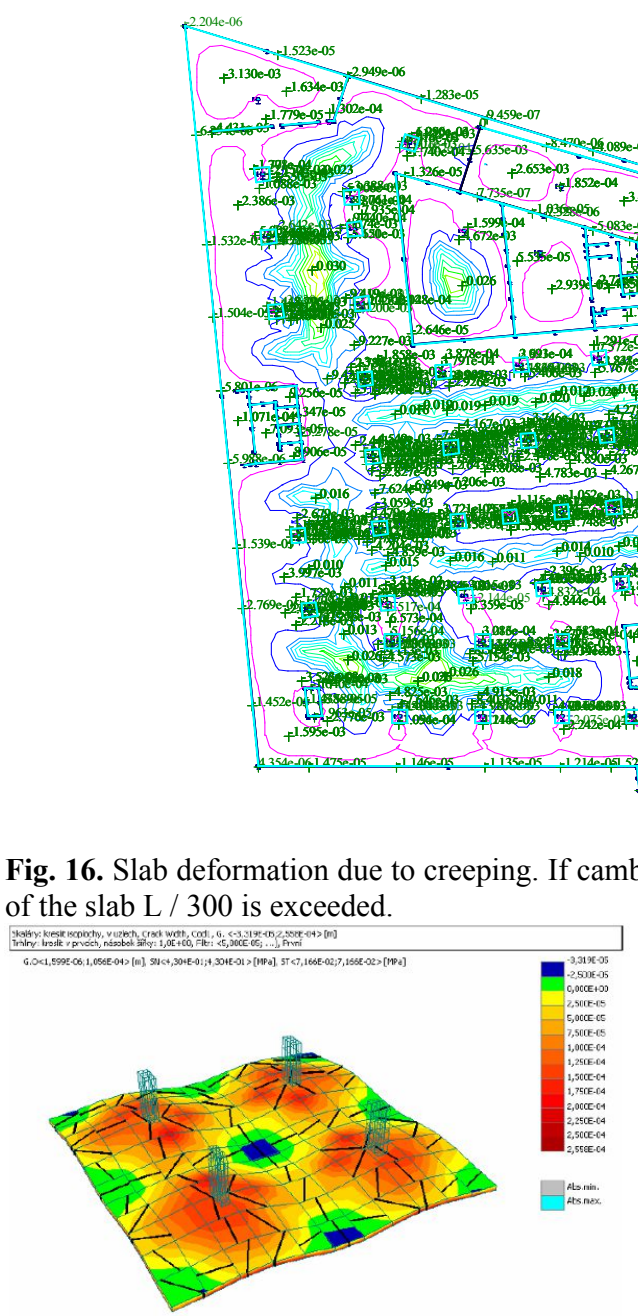

\begin{tabular}{|c|}
\hline Def.[m] \\
$\mathrm{s}$ dotvarovánim \\
-0.041 \\
$-0.038-$ \\
$-0.035-$ \\
-0.032 \\
-0.029 \\
-0.026 \\
-0.024 \\
$-0.021-$ \\
$-0.018-$ \\
-0.015 \\
$-0.012-$ \\
$-9.257 \mathrm{e}-003$ \\
$-6.407 \mathrm{e}-03$ \\
$-3.557 \mathrm{e}-003$ \\
$-7.067 \mathrm{e}-004$ \\
$2.143 \mathrm{e}-003$ \\
\hline
\end{tabular}

Fig. 16. Slab deformation due to creeping. If cambering of slabs not performed, the limit deformation of the slab L / 300 is exceeded.

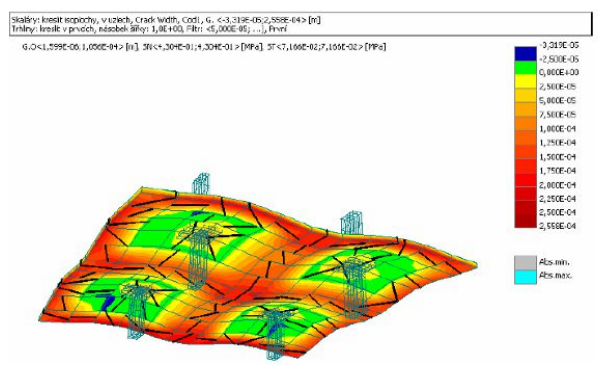

Fig. 17, 18. Diagram of cracks on the upper and lower slab faces, max. crack width $0.26 \mathrm{~mm}$ 

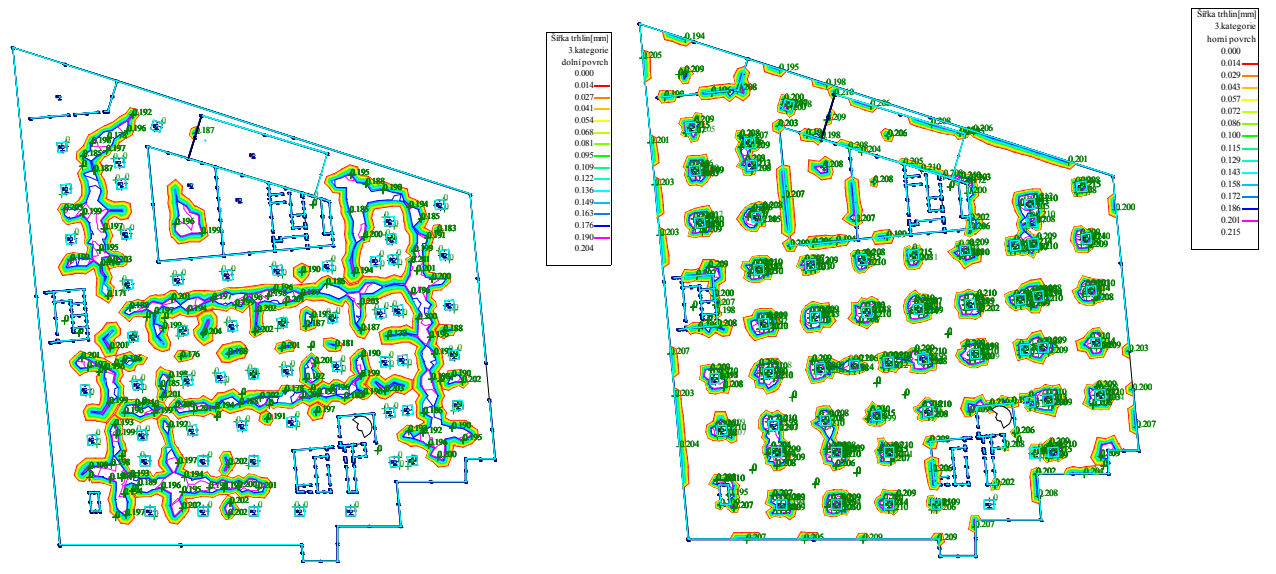

Fig. 19, 20. Cracks on the lower surface of the slab. Cracks on the upper surface of the slab.

\subsection{Model evaluation and conclusions:}

During load operation the slab deflection reached around $20 \mathrm{~mm}$. The measured values are approximately twice this value. This implies to the premature removal of slab formwork or higher shrinkage due to the inadequate treatment of fresh concrete, possibly lower material properties (concrete elasticity modulus) compared to project expectations.

In the calculations, during operating load crack width reached values of 0.2 to 0.3 millimeters. These cracks formed in mainly as a result of shrinkage (85\%) and led to by their expansion due to overloading. The measured values are in the range of $0.1-0.6 \mathrm{~mm}$, which again demonstrates larger amount of likely shrinkage, in fact contrary to the expectations of the calculation.

\section{Sample remediation of defects:}

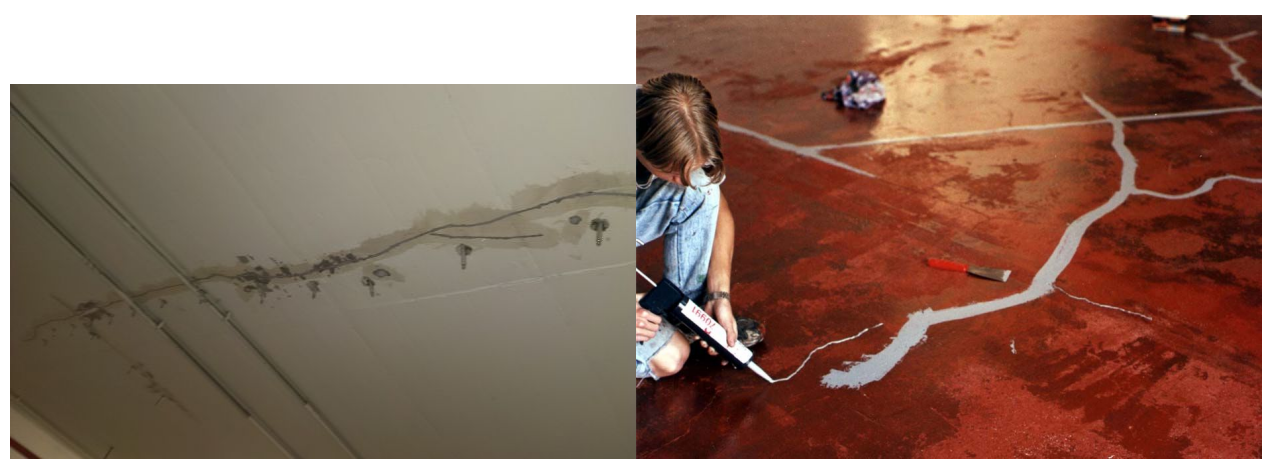

Fig. 21, 22. View of crack grouting by using packers on the lower face and patching on the upper face of the direct running slabs 

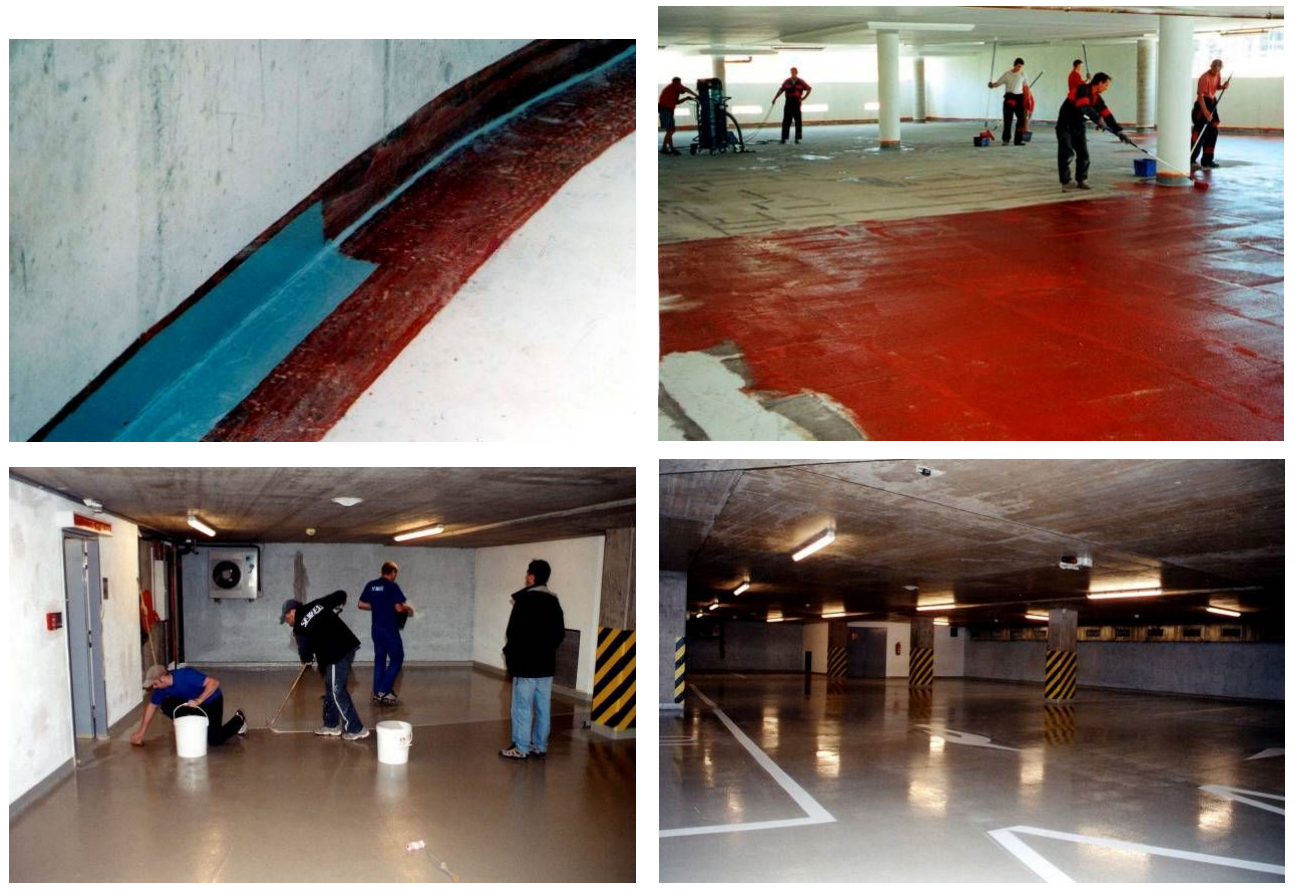

Fig. 23, 26. Implementation of new waterproofing layers using a trowel with sufficient overlap of cracks and their dynamic opening under load and summer/winter temperature changes in the building.

\section{Conclusion}

As the above example shows, the cause of defects in the structure of direct running slabs can be a designer error: insufficient bending reinforcement to reduce cracking in a corrosive environment, in some cases, considering the structure as protected (coating, waterproofing putty in contrast to construction projects and static parts); a contractor error: insufficient treatment, poor use of concrete mixtures without a guaranteed modulus, failure to comply with the defined elevation of ceiling slabs, previous stripping, violations of technological discipline, non-compliance with the time lag between different parts of concrete slabs in case of using shrinkage belts and so along with others.

\section{References}

1. ČSN 731373 - Hardness-testing Methods for Testing Concrete Under Pressure

2. ČSN EN 206-Z1-Z4 Concrete - Part 1: Specification, Performance, Production and Conformity

3. ČSN ISO 6713 Concrete. Determination of Static Elasticity Modulus Under Pressure

4. CSN EN 1992-1-1 Eurocode 2: Design of Concrete Structures. Part 1-1: General Rules and Rules for Buildings

5. Č́SN EN 13670 Execution of Concrete Structures

6. ČSN ISO 13822 Principles of Structural Design - Assessment of Existing Structures

7. (ČSN 73 0038) Design and Assessment of Building Structures During Rebuilding 